J Gynäkol Endokrinol 2018·21:3

https://doi.org/10.1007/s41975-018-0036-2

(c) Springer-Verlag GmbH Austria, ein Teil von Springer Nature 2018

CrossMark

\title{
P. Stute
}

Service de gynécologie endocrinologique et de médecine de la reproduction, Clinique universitaire de gynécologie et obstétrique, Inselspital de Berne, Berne, Suisse

\section{Éditorial}

Chère consœur,

Cher confrère,

Tout d'abord, je vous souhaite une excellente année 2018, avec une dose supplémentaire de santé, de sérénité et de bonheur!

Il semble que la chance a moins souri à des femmes immigrées de zones de crise, que nous rencontrons de plus en plus souvent dans la situation quotidienne: les femmes ayant subi des mutilations génitales. Cette pratique aujourd'hui considérée comme une violation des droits de l'homme est passible d'une peine dans la plupart des pays. On estime néanmoins que 0,5 million de femmes sont concernées dans l'UE. Quelle est la meilleure attitude à adopter auprès de ces femmes? Comment l'accouchement par voie basse peut-il réussir? Ces questions font partie des thèmes de l'article d'A. Wohlfahrt \& C. Brucker, qui présentent entre autres leurs propres expériences et données de Nuremberg.

Le deuxième article se penche sur un thème central de l'endocrinologie gynécologique chez la femme en âge de procréer: le SOPK. De nombreuses femmes atteintes luttent souvent toute leur vie contre l'excès de poids. Quelle pourrait être la solution? Metformine forever? Larticle de W. Schnedl \& M. Schenk encourage à reprendre malgré tout le thème des adaptations du mode de vie et donne des conseils pratiques.

J'espère que vous y trouverez de quoi vous intéresser et vous instruire!

Bien à vous,

Petra Stute

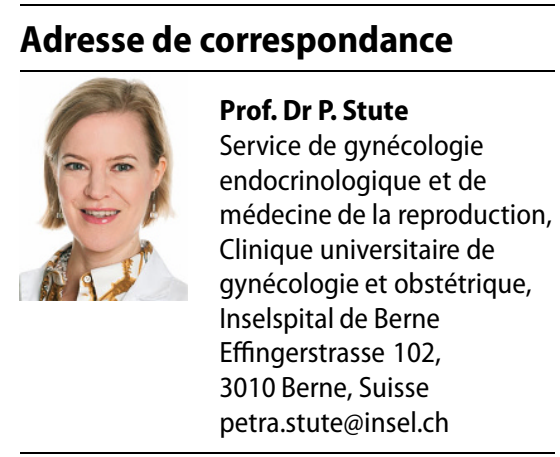

Conflit d'intérêts. P. Stute déclare ne pas avoir de conflit d'intérêt. 